\title{
AKTIVITAS ANTIOKSIDAN KULIT BUAH PIDADA MERAH (SONNERATIA CASEOLARIS L.)
}

\author{
Vinny Sukma Wijayana Putri, Victoria Yulita, Laode Rijai \\ Laboratorium Penelitian dan Pengembangan FARMAKA TROPIS Fakultas Farmasi \\ Universitas Mulawarman, Samarinda, Kalimantan Timur \\ email: vn2ya@yahoo.com
}

\begin{abstract}
ABSTRAK
Judul penelitian ini yaitu Aktivitas Antioksidan Kulit Buah Pidada Merah (Sonneratia Caseolaris L.). Penelitian ini dilakukan dengan metode DPPH (1,1-diphenyl-2picrylhydrazyl) secara spektrofotometri untuk uji daya antioksidan ekstrak kulit buah pidada merah. Ekstrak yang digunakan dalam penelitian ini adalah dalam bentuk ekstrak kasar dan ekstrak fraksi dengan berbagai pelarut, yakni metanol, $n$-heksana, etil asetat, dan $n$-butanol. Pada penelitian ini, dilihat aktivitas antioksidan ekstrak kulit buah pidada merah, pengaruh variasi konsentrasi ekstrak terhadap DPPH, nilai IC50 masing-masing ekstrak. Analisis data yang digunakan adalah dengan persamaan regresi linier. Hasil pengujian aktivitas antioksidan kulit buah pidada merah terhadap DPPH menunjukkan IC50 masing masing-masing yaitu ekstrak metanol $25,72 \mathrm{ppm}$, ekstrak fraksi $n$-heksana $67,48 \mathrm{ppm}$, ekstrak etil asetat $109,24 \mathrm{ppm}$ dan fraksi $n$-butanol $54,29 \mathrm{ppm}$. Dari data tersebut diketahui bahwa ektrak kulit buah pidada merah memiliki aktivitas antioksidan yang baik.
\end{abstract}

Kata Kunci: Ekstrak Kulit Buah Pidada merah, Antioksidan, $\mathrm{IC}_{50}$.

\section{PENDAHULUAN}

Salah satu tumbuhan yang bermanfaat sebagai obat ialah tumbuhan pidada merah (Sonneratia caseolaris L.) atau di masyarakat dikenal dengan nama rambai padi. Sonneratia caseolaris adalah salah satu spesies tanaman mangrove. Sonneratia adalah salah satu dari berbagai jenis tanaman dari ekosistem mangrove yang sering dimanfaatkan untuk keperluan di bidang farmakologi dan konsevasi lingkungan (Untung, 2007).

Masyarakat banyak menggunakan pidada sebagai obat tradisional khususnya di Kalimantan Selatan, buah dan daun rambai atau pidada merah ini sering dijadikan bahan ramuan bedak dingin serta obat luka dan penghilang bekas luka (Heyne, 1987).

Pidada merah diketahui memiliki kandungan senyawa bioaktif seperti flavanoid, steroid, fenol hidrokuinon dan tanin. Pada bagian buah pidada merah memiliki kandungan senyawa flavanoid (Sadhu, et all 2006).

Selain itu, tanaman pidada merah pada bagian buah mengandung komponen kimia senyawa fenol dan tanin (Nairborhu, 2002).

Antioksidan merupakan senyawa yang dalam kadar rendah dibanding bahan yang dapat dioksidasi, sangat memperlambat atau menghambat oksidasi bahan tersebut.Antioksidan merupakan senyawa pemberi elektron (elektron donor) atau reduktan. (Silalahi, 2006).

Kandungan flavanoid ini yang membuat peneliti tertarik untuk menguji aktivitas antioksidan pada kulit buah dengan harapan kandungan yang terdapat pada buah terdapat pula pada kulit. 


\section{METODE PENELITIAN}

\section{Bahan}

Bahan yang diteliti adalah tumbuhan pidada merah (Sonneratia caseolaris L.), bagian yang diteliti adalah kulit buah. Bahan penelitian : air suling, metanol, n-heksanaa, etil asetat dan nbutanol pereaksi DPPH (1,1diphenyl-2-picrylhydrazyl).

\section{Peralatan}

Peralatan yang digunakan dalam penelitian ini antara lain rotary evaporator, seperangkat alat maserasi, waterbath, tabung reaksi bertutup, labu ukur, mikro pipet, pipet volume, vortex, timbangan digital, spektrofotometer UVVis (Genesys IOS UV-Vis Spectrophotometer).

\section{Prosedur pengambilan dan pengolahan sampel}

Bahan berupa kulit buah pidada merah segar yang diambil ditepi sungai Mahakam Jalan Untung suropati, Samarinda Kalimantan Timur. Buah segar dibersihkan, diambil bagian kulitnya, dicuci, dirajang kemudian dikeringkan tanpa melalui sinar matahari.

\section{Prosedur ekstraksi dan fraksinasi}

Simplisia kering 200 gram yang diperoleh dari sampel segar 500 gram diekstraksi dengan menggunakan metode maserasi selama 5 hari menggunakan pelarut metanol, sehingga diperoleh 18,5 gram ekstrak kasar. Selanjutnya difraksinasi dengan menggunakan metode fraksinasi cair-cair, diperoleh fraksi n-heksana 4 gram, fraksi etil asetat 3,5 gram dan fraksi n butanol 1,5 gram.

\section{Prosedur pengujian}

Diambil $2 \mathrm{~mL}$ larutan ekstrak kemudian ditambahkan dengan $2 \mathrm{~mL}$ larutan DPPH 40 ppm.Variasi konsentrasi ekstrak metanol 10 ppm, 30 ppm, 50 ppm, fraksi n-heksana $10 \mathrm{ppm}$, $50 \mathrm{ppm}, 90 \mathrm{ppm}, 150 \mathrm{ppm}$, fraksi etil asetat $10 \mathrm{ppm}, 30 \mathrm{ppm}, 50 \mathrm{ppm}, 70 \mathrm{ppm}$, 90 ppm, 110 ppm, 150 ppm, fraksi nbutanol 10 ppm, 50 ppm, 70 ppm dan 90 ppm. Campuran larutan ini dihomogenkan dengan menggunakan vorteks dan dibiarkan di tempat gelap pada suhu kamar selama 30 menit. Kemudian diukur absorbansinya pada panjang gelombang tertentu.

Tabel 1. Nilai Absorbansi dan Persen Aktivitas Antioksidan Ekstrak Metanol Kulit Buah Pidada Merah

\begin{tabular}{|c|c|c|c|c|c|c|}
\hline No. & $\begin{array}{l}\text { Konsentrasi } \\
\text { (ppm) }\end{array}$ & Absorbansi & $\begin{array}{l}\text { Aktivitas } \\
\text { antioksidan } \\
(\%)\end{array}$ & $\begin{array}{l}\text { Rata-rata } \\
\text { aktvitas } \\
\text { antioksidan }\end{array}$ & $\begin{array}{l}\text { Perhitungan } \\
\text { regresi linier }\end{array}$ & $\begin{array}{l}\text { IC50 } \\
\text { (ppm) }\end{array}$ \\
\hline \multirow{3}{*}{1} & \multirow{3}{*}{10} & 0,450 & 32,64 & \multirow{3}{*}{32,24} & \multirow{12}{*}{$y=0,9865 x+24,635$} & \multirow{12}{*}{25,72} \\
\hline & & 0,411 & 38,48 & & & \\
\hline & & 0,415 & 37,88 & & & \\
\hline \multirow{4}{*}{2} & \multirow{4}{*}{30} & 0,265 & 60,33 & \multirow{4}{*}{58,75} & & \\
\hline & & 0,281 & 57,93 & & & \\
\hline & & 0,281 & 57,93 & & & \\
\hline & & 0,275 & 58,83 & & & \\
\hline \multirow{5}{*}{3} & \multirow{5}{*}{50} & 0,186 & 72,15 & \multirow{5}{*}{71,7} & & \\
\hline & & 0,190 & 71,55 & & & \\
\hline & & 0,182 & 72,75 & & & \\
\hline & & 0,190 & 71,55 & & & \\
\hline & & 0,197 & 70,50 & & & \\
\hline
\end{tabular}

Keterangan : Absorbansi kontrol DPPH yaitu 0,669 
Tabel 2. Nilai Absorbansi dan Persen Aktivitas Antioksidan Ekstrak Metanol Kulit Buah Pidada Merah

\begin{tabular}{|c|c|c|c|c|c|c|}
\hline No. & $\begin{array}{l}\text { Konsentrasi } \\
\text { (ppm) }\end{array}$ & Absorbansi & $\begin{array}{l}\text { Aktivitas } \\
\text { antioksidan } \\
(\%)\end{array}$ & $\begin{array}{c}\text { Rata-rata } \\
\text { aktvitas } \\
\text { antioksidan }\end{array}$ & $\begin{array}{l}\text { Perhitungan } \\
\text { regresi linier }\end{array}$ & $\begin{array}{l}\mathrm{IC} 50 \\
(\mathrm{ppm})\end{array}$ \\
\hline \multirow{5}{*}{1} & \multirow{5}{*}{10} & 0,405 & 34,14 & \multirow{5}{*}{35,86} & \multirow{20}{*}{$y=0,2737 x+31,53$} & \multirow{20}{*}{67,48} \\
\hline & & 0,403 & 34,47 & & & \\
\hline & & 0,402 & 34,63 & & & \\
\hline & & 0,399 & 35,12 & & & \\
\hline & & 0,363 & 40,97 & & & \\
\hline \multirow{5}{*}{2} & \multirow{5}{*}{50} & 0,344 & 44,06 & & & \\
\hline & & 0,349 & 43,25 & & & \\
\hline & & 0,357 & 41,95 & 44,06 & & \\
\hline & & 0,353 & 42,60 & & & \\
\hline & & 0,317 & 48,45 & & & \\
\hline \multirow{5}{*}{3} & \multirow{5}{*}{90} & 0,238 & 61,30 & & & \\
\hline & & 0,289 & 53,00 & & & \\
\hline & & 0,294 & 52,19 & 54,37 & & \\
\hline & & 0,290 & 52,84 & & & \\
\hline & & 0,292 & 52,52 & & & \\
\hline \multirow{5}{*}{4} & \multirow{5}{*}{150} & 0,168 & 72,68 & \multirow{5}{*}{73,94} & & \\
\hline & & 0,163 & 73,49 & & & \\
\hline & & 0,154 & 74,95 & & & \\
\hline & & 0,161 & 73,82 & & & \\
\hline & & 0,155 & 74,79 & & & \\
\hline
\end{tabular}

Keterangan : Absorbansi kontrol DPPH yaitu 0,615

\section{HASIL DAN PEMBAHASAN}

\section{Aktivitas Antioksidan Ekstrak Kasar}

Dari Tabel 1. dapat dilihat bahwa semakin besar konsentrasi sampel maka semakin besar pula aktivitas antioksidannya. Hal ini dikarenakan semakin tinggi konsentrasi maka semakin tinggi pula kandungan zat antioksidannya, sehingga semakin banyak DPPH yang dihambat oleh ekstrak tersebut dan semakin sedikit DPPH yang tersisa, oleh karena itu aktivitas antioksidannya semakin besar.

\section{Aktivitas Antioksidan Fraksi n-heksan Kulit Buah Pidada Merah}

Berdasarkan Tabel 2 menunjukan bahwa nilai $\mathrm{IC}_{50}$ ekstrak fraksi $n$-heksana adalah 67,65 ppm. Hal ini menunjukan bahwa aktivitas antioksidan ekstrak fraksi n- heksana kulit buah pidada merah adalah aktif. Aktivitas antioksidan selalu meningkat seiring dengan peningkatan konsentrasi. Grafik ini menunjukkan hubungan antara nilai aktivitas fraksi $n$-heksana dengan variasi konsentrasi uji.

\section{Aktivitas Antioksidan Fraksi Etil Asetat Kulit Buah Pidada Merah \\ Berdasarkan Tabel 3 menunjukan bahwa nilai $\mathrm{IC}_{50}$ ekstrak fraksi etil asetat adalah 109,24 ppm. Hal ini menunjukan bahwa aktivitas antioksidan ekstrak fraksi etil asetat kulit buah pidada merah adalah aktif. Aktivitas antioksidan selalu meningkat seiring dengan peningkatan konsentrasi. Grafik ini menunjukkan hubungan antara nilai aktivitas fraksi etil asetat dengan variasi konsentrasi uji.}


Tabel 3. Nilai Absorbansi dan Persen Aktivitas Antioksidan Ekstrak Metanol Kulit Buah Pidada Merah

\begin{tabular}{|c|c|c|c|c|c|c|}
\hline No. & $\begin{array}{l}\text { Konsentrasi } \\
\quad(\mathrm{ppm})\end{array}$ & Absorbansi & $\begin{array}{l}\text { Aktivitas } \\
\text { antioksidan } \\
(\%)\end{array}$ & $\begin{array}{c}\text { Rata-rata } \\
\text { aktvitas } \\
\text { antioksidan }\end{array}$ & $\begin{array}{l}\text { Perhitungan } \\
\text { regresi linier }\end{array}$ & $\begin{array}{l}\mathrm{IC}_{50} \\
(\mathrm{ppm})\end{array}$ \\
\hline \multirow{5}{*}{1} & \multirow{5}{*}{10} & 0,549 & 1,78 & \multirow{5}{*}{1,74} & \multirow{35}{*}{$y=0,470 x+-1,346$} & \multirow{35}{*}{109,24} \\
\hline & & 0,549 & 1,78 & & & \\
\hline & & 0,550 & 1,61 & & & \\
\hline & & 0,550 & 1,61 & & & \\
\hline & & 0,548 & 1,96 & & & \\
\hline \multirow{5}{*}{2} & \multirow{5}{*}{30} & 0,477 & 14,66 & \multirow{5}{*}{15,59} & & \\
\hline & & 0,475 & 15,02 & & & \\
\hline & & 0,464 & 16,99 & & & \\
\hline & & 0,475 & 15,02 & & & \\
\hline & & 0,468 & 16,27 & & & \\
\hline \multirow{5}{*}{3} & \multirow{5}{*}{50} & 0,437 & 21,82 & \multirow{5}{*}{21,92} & & \\
\hline & & 0,432 & 22,71 & & & \\
\hline & & 0,437 & 21,82 & & & \\
\hline & & 0,437 & 21,82 & & & \\
\hline & & 0,439 & 21,46 & & & \\
\hline \multirow{5}{*}{4} & \multirow{5}{*}{70} & 0,430 & 23,07 & & & \\
\hline & & 0,424 & 24,15 & & & \\
\hline & & 0,401 & 28,26 & 27,58 & & \\
\hline & & 0,412 & 26,29 & & & \\
\hline & & 0,357 & 36,13 & & & \\
\hline \multirow{5}{*}{5} & \multirow{5}{*}{90} & 0,309 & 44,72 & \multirow{5}{*}{45,25} & & \\
\hline & & 0,307 & 45,08 & & & \\
\hline & & 0,306 & 45,25 & & & \\
\hline & & 0,304 & 45,61 & & & \\
\hline & & 0,304 & 45,61 & & & \\
\hline \multirow{5}{*}{6} & \multirow{5}{*}{90} & 0,286 & 48,83 & \multirow{5}{*}{49,97} & & \\
\hline & & 0,276 & 50,62 & & & \\
\hline & & 0,277 & 50,44 & & & \\
\hline & & 0,279 & 50,08 & & & \\
\hline & & 0,280 & 49,91 & & & \\
\hline \multirow{5}{*}{7} & \multirow{5}{*}{90} & 0,177 & 68,33 & \multirow{5}{*}{68,54} & & \\
\hline & & 0,177 & 68,33 & & & \\
\hline & & 0,175 & 68,69 & & & \\
\hline & & 0,175 & 68,69 & & & \\
\hline & & 0,175 & 68,69 & & & \\
\hline
\end{tabular}

Keterangan : Absorbansi kontrol DPPH yaitu 0,559 
Tabel 4. Nilai Absorbansi dan Persen Aktivitas Antioksidan Ekstrak Fraksi $n$-butanol Kulit Buah Pidada Merah

\begin{tabular}{|c|c|c|c|c|c|c|}
\hline No. & $\begin{array}{l}\text { Konsentrasi } \\
\quad(\mathrm{ppm})\end{array}$ & Absorbansi & $\begin{array}{l}\text { Aktivitas } \\
\text { antioksidan } \\
(\%)\end{array}$ & $\begin{array}{c}\text { Rata-rata } \\
\text { aktvitas } \\
\text { antioksidan }\end{array}$ & $\begin{array}{l}\text { Perhitungan } \\
\text { regresi linier }\end{array}$ & $\begin{array}{l}\mathrm{IC} \mathrm{I}_{50} \\
(\mathrm{ppm})\end{array}$ \\
\hline \multirow{5}{*}{1} & \multirow{5}{*}{10} & 0,426 & 7,59 & \multirow{5}{*}{12,70} & \multirow{20}{*}{$y=0,790 x+7,104$} & \multirow{20}{*}{54,29} \\
\hline & & 0,394 & 14,53 & & & \\
\hline & & 0,403 & 12,58 & & & \\
\hline & & 0,397 & 13,88 & & & \\
\hline & & 0,392 & 14,96 & & & \\
\hline \multirow{5}{*}{2} & \multirow{5}{*}{50} & 0,223 & 51,62 & \multirow{5}{*}{48,97} & & \\
\hline & & 0,220 & 52,27 & & & \\
\hline & & 0,263 & 48,80 & & & \\
\hline & & 0,239 & 38,15 & & & \\
\hline & & 0,212 & 54,01 & & & \\
\hline \multirow{5}{*}{3} & \multirow{5}{*}{70} & 0,198 & 57,04 & \multirow{5}{*}{66,98} & & \\
\hline & & 0,124 & 68,76 & & & \\
\hline & & 0,142 & 69,19 & & & \\
\hline & & 0,143 & 68,98 & & & \\
\hline & & 0,134 & 70,93 & & & \\
\hline \multirow{5}{*}{4} & \multirow{5}{*}{90} & 0,136 & 70,49 & \multirow{5}{*}{73,66} & & \\
\hline & & 0,124 & 73,10 & & & \\
\hline & & 0,122 & 73,53 & & & \\
\hline & & 0,118 & 74,40 & & & \\
\hline & & 0,107 & 76,78 & & & \\
\hline
\end{tabular}

Keterangan : Absorbansi kontrol DPPH yaitu 0,461

\begin{abstract}
Aktivitas Antioksidan Fraksi nbutanol Kulit Buah Pidada Merah

Berdasarkan Tabel 4 menunjukan bahwa nilai $\mathrm{IC}_{50}$ ekstrak fraksi n-butanol adalah 54,29 ppm. Hal ini menunjukan bahwa aktivitas antioksidan ekstrak fraksi n-butanol kulit buah pidada merah adalah aktif. Aktivitas antioksidan selalu meningkat seiring dengan peningkatan konsentrasi. Grafik ini menunjukkan hubungan antara nilai aktivitas fraksi $n$ butanol dengan variasi konsentrasi uji.
\end{abstract}

\section{KESIMPULAN}

Aktivitas antioksidan kulit buah pidada merah dengan parameter IC50 terhadap DPPH pada ekstrak metanol, ekstrak fraksi n-heksana, etil asetat, dan n-butanol adalah 25,72 ppm, 67,48 ppm, 109,24 ppm, dan 54,29 ppm.

\section{DAFTAR PUSTAKA}

1. Heyne, K. 1987. Tumbuhan Berguna Indonesia Jilid III. Badan Litbang Kehutanan: Jakarta.

2. Naiborhu, P.E. 2002. Ekstraksi dan Manfaat Ekstrak Mangrove (Sonneratia Caseolaris dan Sonneratia alba) sebagai Bahan Alam antibakterial Pada Patogen Udang Windu, Vibrio harveyi. Tesis, Fakultas Perikanan dan Ilmu kelautan, Institut Pertanian Bogor: Bogor.

3. Sadhu, S. K., F. Ahmed, T. Ohtsuki, dan M. Ishibashi. 2006. Flavonoids from Sonneratia caseolaris. Journal of Natural Medicine 60: 264-265.

4. Silalahi, J. 2006. Makanan Fungsional. Kanisius: Yogyakarta. 
Aktivitas Antioksidan Kulit Buah Pidada Merah (Sonneratia caseolaris L.)

5. Untung, Moch., Kurnia, 2007. Penelusuran Efektifitas Beberapa Bahan Alam Sebagai Kandidat Antibakteri Dalam Mengatasi Penyakit Vibriosis Pada Udang Windu. Universitas Padjajaran: Bandung. 